\section{De novo translocation involving chromosomes 2, 8, and 20}

The proband is a male child born at term to a 26 year old mother (gravida 3, para 2) and a 23 year old father. There is no family history of miscarriages, malformations, or mental handicap. The first child was normal. The second pregnancy was terminated for social reasons. Examination of the proband at $4 \frac{1}{2}$ years of age (fig 1) showed a dolichocephalic skull; low, obliquely set, malformed, and protruding ears; antimongoloid palpebral fissures; epicanthic folds; broad nasal bridge; full cleft of the soft palate with partial cleft of the hard palate; micrognathia; short neck; convex thorax and platypodia. The child is severely mentally retarded, cannot speak, does not recognise his relatives, and is unable to obey instructions. Chromosome preparations were obtained from cultured blood lymphocytes and were GTG banded. All the cells analysed showed a three-way rearrangement involving chromosomes 2,8 , and 20 . The karyotype was interpreted as $46, \mathrm{XY}, \mathrm{t}(2 ; 8 ; 20)(2 \mathrm{pter} \rightarrow 2 \mathrm{q} 23:: 20 \mathrm{q} 11 \cdot 2 \rightarrow$ 20 qter ;8pter $\rightarrow 8$ q $22:: 2 q 23 \rightarrow 2$ qter $; 20$ pter $\rightarrow 20$ q $11 \cdot 2:: 8 q 22$ $\rightarrow$ qqter) (fig 2). The chromosomes of the proband's parents and his elder brother were normal.

Although the translocations appear to be balanced it is most unlikely that the child's developmental abnormalities are fortuitous. It is probable that minute deletion/ duplications of chromosome material have occurred but they are too small to be detected.

It is reasonable to assume that a singular cell event

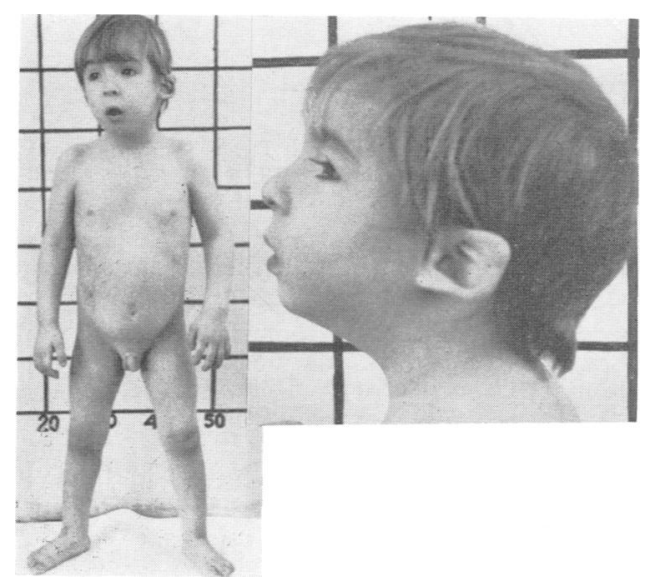

FIG 1 Phenotype of the proband.

Received for publication 12 April 1983. Accepted for publication 9 June 1983.

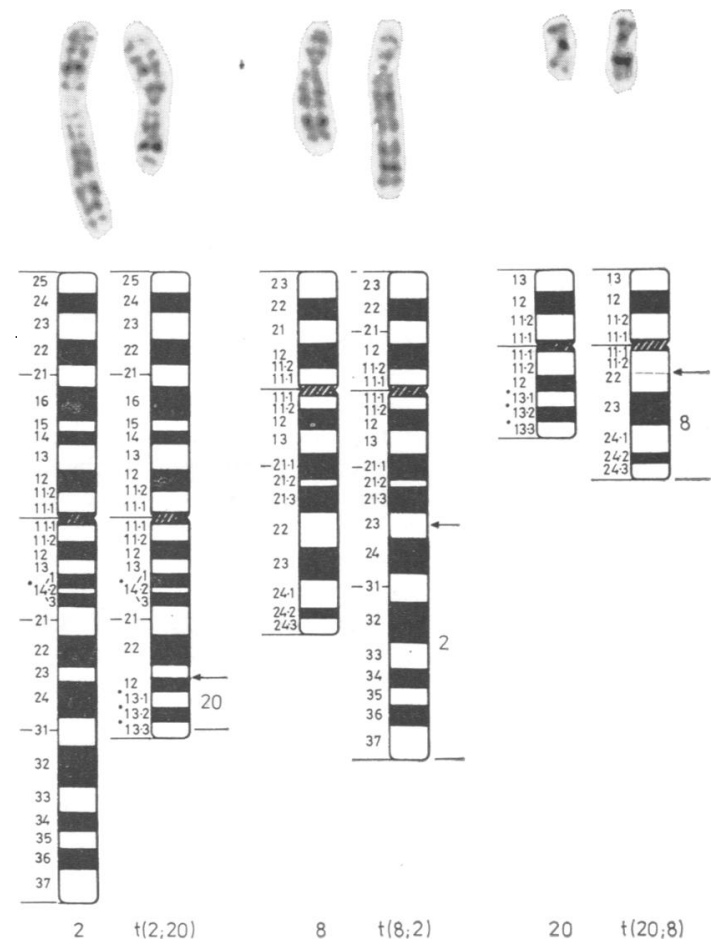

FIG $2 G$ banding pattern of chromosomes 2, 8, and 20 and diagram of the complex rearrangement of these chromosomes.

determined the simultaneous occurrence of the three breaks and that the translocations originated either in a gametic nucleus or in the very early embryo.

The authors are most grateful to Professor A F Zakharov and Dr N P Kuleshov for help in discussing the case.

D V ZALETAJEV, G S MARINCHEVA, AND
T G TSVETKOVA
Institute of Medical Genetics,
Academy of Medical Sciences of the USSR,
and Institute of Psychiatry,
Ministry of Health of RSFSR,
Moscow, USSR.

Correspondence and requests for reprints to $\mathrm{Dr} \mathrm{D} \mathrm{V}$ Zaletajev, Institute of Medical Genetics of the AMS USSR, Moscvorechye 1, Moscow 115478, USSR. 